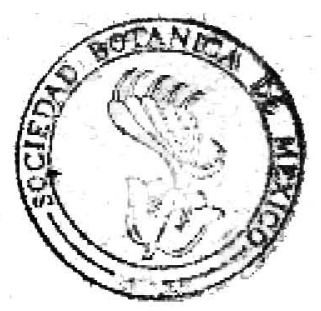

\title{
LAS COMPUESTAS DEL VALLE CENTRAL DE MEXICO
}

\author{
POR EL, DR, LADISLAO PARAY.
}

Continuamos la descripción de los géneros y especies de la familia Compuestas del Valle Central de México. En primer lugar describiremos los géneros que tienen pocas especies, dejando los de muchas para más tarde, ya que éstos requieren más investigaciones y observaciones. En los siguientes trabajos no seguiremos un orden tiguroso de subfamilias o tribus, sino trataremos aquellos géneros de los cuales, a nuestro parecer, tenemos suficientes datos.

\section{SELLOA. Spreng. Nov. Prov. Hal. 36, 1819.}

Este género, que pertenece a la tribu Asteroideas, tiene dos especies en el Valle, tan diferentes entre si, que en lugar de dar la descripción del género preferimos describir cada especie. Una es arbustiva, con flores pequeñas reunidas en corimbos paniculados: es la $S$. glutinosa. La otra es herbácea, con flores medianas, solitarias o pocas: es la $S$. plantaginea.

SELLOA GLUTINOSA. Spreng. Nov. Prov. Hal. 36, 1819.

Gymnosperma glutinosum Less. Syn. Gen. Comp. 194, 1832.

Gymnospermu corymbosum DC. Prodr. 5; 312, 1836 .

Gumnosperme multiflorum DC. Ptodr. 5; 312, 1836.

Gymnosperma scoparium DC. Prodt. 5; 312, 1836.

Es un arbusto hasta de $1 \mathrm{~m}$. de alto, con las ramas bajas leñosas, muy ramoso. Toda la planta es lisa y sumamente pegajosa (de 
SOCIEDAd BotÁnICA dE MÉxico.-Bol. 15-1953

aqui el nombre glutinosa). Las bojas son alternas y sésiles, frecuentemente con fasciculos en las axilas: lineares o angostamente elipticolanceoladas, de 2 a $7 \mathrm{~cm}$. de largo y de 2 a $6 \mathrm{~mm}$. de ancho: trinetvadas, enteras y llenas de puntitos. Las cabezuelas son amarillas. aproximadamente de $4 \mathrm{~mm}$. de alto, reunidas en corimbos paniculados, densos: brácteas del invólucro pálidas, subcoriáceas, obtusas, con bordes angostos y delgados, a veces con el ápice herbáceo. Las ligulas son en número de $6 \mathrm{y}$ no sobresalen del disco: flores del disco aproximadamente 6 ; aquenios oblongos, veilosos, con 4 ó 5 aristas: vilano ausente.

Nombre vulgar en el Valle de México: "pegajosa" o "escobilla". En la medicina popular, una infusión de la planta se emplea como remedio contra la diarrea y una solución de la substancia resinosa para combatir el reumatismo y las úlceras.

Distribución: de Chibuahua hasta Chiapas: Texas y Arizona Valle de Mexico: abunda en la Sierra de Guadalupe y en otros cerros al notte de la capital como el cerro de Patlachique; región de San Juan Teotihuacán, etc. En general, esta planta prefiete los terrenos calcáreos, secos y asoleados. Crece en alturas diferentes, desde el nivel del mar hasta $\operatorname{los} 2500 \mathrm{~m}$. Sin embargo, en el centro de la República nunca baja de los $1000 \mathrm{~m}$. Es planta atractiva. Flotece en la época de lluvias, desde junio hasta octubre.

SELLOA PLANTAGINEA HBK. 4. 209. Nov. Geth. Sp. II.

Sabazia subruda Rob. Bs Sci. Proc. Am. Acas. $28,108$.

Hierba perenne, de unos 15 a $20 \mathrm{~cm}$. de alto, con los tallos vellosos, por lo regular desprovistos de hojas a manera de escapos, o con pocas hojas pequeñas. Hojas en roseta basilar, subsésiles, de 3 a $5 \mathrm{~cm}$. de largo $y$ de 1 a 2 de ancho, de forma oblonga. A pice obtuso $y$ base cuneada. Cabezuelas medianas, solitarias o por pares; de dos a tres $\mathrm{cm}$. de diámetro $\mathrm{y}$ de $\mathrm{I}$ a 1.5 de alto, heterógamas, con las flores periféricas uniseriadas y femeninas: las del disco son tubulosas y hermafroditas. Las ligulas son tridentadas, blancas o rosadas. de 1 a $1.5 \mathrm{~cm}$. de largo. Invólucro campanulado con dos a tres series 
SOCIEDAd BotÁNICA de MÉxICO.-BOL, 15-1953

de brácteas anchas. Receptáculo cónico, con las pajitas angostisimas. Anteras con la base obtusa. Aquenios cuneados, lampiños, prismáticos con cinco aristas: el vilano de tres a cinco cerdas caedizas.

Distribución: Altas montañas del centro de la República: Michoacátn, México, Valle de México, en las montañas elevadas del sur de la capital, como en la Sierra de las Cruces. Es muy escasa, nos-

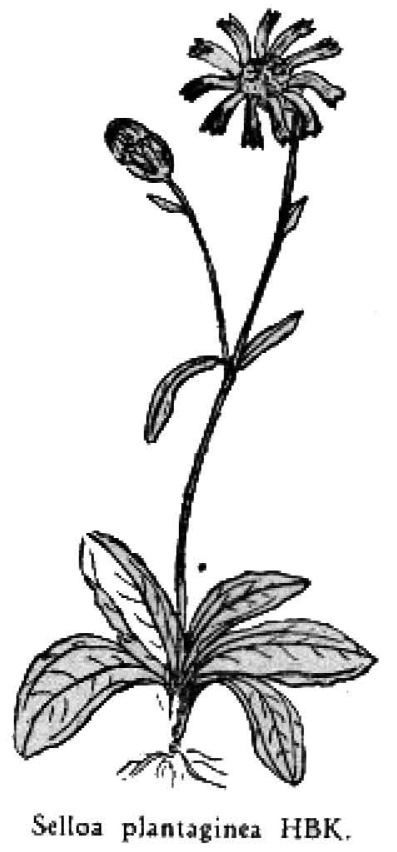

otros la encontramos en las faldas del cerro San Miguel a una altura de unos $3400 \mathrm{~m}$. en bosques de pinos y oyameles. Reiche, en su obra "Flora Excursoria del Valle Central de México", dice: "se ignora la localidad especial de ta planta". Por su escasez y por su tamaño pequeño fácilmente escapa al observador. Es curioso que a otros botánicos se les haya también escapado. Humboldt publicó un dibujo en su obra Nov. Gen. et Sp. Pl. IV. 209, lámina 395, que representa perfectamente la planta. A pesar de la claridad del dibujo, durante largo tiempo ningún botánico la habia encontrado. Robinson y Sea. 


\section{SOCIEDAD BOTÁNICA DE MÉXICO-BOL. 15-1953}

ton la clasificaron como Sabazia subnuda. Asi figuró esta planta durante muchos años en los herbarios del mundo, hasta que por fin dichos botánicos, percatándose del etror, rectificaton la clasificación por unos ejemplares de Pringle colectados en el Nevado de Toluca. En una descripción del género Sabazia dicen: "queda excluida la especie Sabazia subnuda ya que esta planta es indudablemente la Selloa plantaginea HBK."

\section{AGERATUM L. Sp. Pl. 839, 1753 .}

Referencia: Robinson, Revisión del género Ageratum Proc. Amer. Acad. 49 454-483-1913. Hierbas o arbustos con las bojas regularmente opuestas o las superiores alternas, ovadas o lanceoladas. Cabezuelas homógamas, medianas o pequeñas, corimbosas, generalmente con pedúnculos largos; invólucto campanulado, de 2 a $3 \mathrm{fi}$ las de brácteas angostas, del mismo largo. Receptáculo plano o poco convexo, desnudo o con pajitas caducas; aquenios prismáticos con 4 ó 5 aristas. Anteras con la base obtusa. Ramitas del estilo largas. agudas. Vilano variado, de escamas obtusas o estiradas en punta o púas, libres o unidas en la base: Flores blancas o azules. Más de treinta especies, principalmente americanas, de las cuales hay dos en el Valle de México. El nombre Ageratum quiere decir "no envejece".

Brácteas del invólucro oblongas, a veces con los bordes más o menos dentados, algo vellosos; flores más pequeñas, planta herbácea y muy ramificada, hojas membranosas: Ageratum conyzoides $\mathrm{L}$.

Brácteas de invólucro agudas y angostas con vellos encrespa. dos; flores más grandes, menos ramificadas, arbustivo $\mathrm{y}$ las hojas coriáceas y ásperas: Ageratum corymbosum.

\section{AGERATUM CONYZOIDES I.}

Hierba anual erecta o a veces prostrada, de 25 a $90 \mathrm{~cm}$. de alto; tallo cilindrico, algo velloso, hojoso. Ramas ascendentes, hojas ovadas, acuminadas, con la base cuneada; dentadas, de 2 a $8 \mathrm{~cm}$. de largo y de 1.5 a 6 de ancho, algo peludas. Corimbos en los extremos 
de los tallos, con 8 a 40 cabezuelas, brevemente pedunculadas. $\mathrm{Pe}$ dúnculos de 3 a $7 \mathrm{~mm}$. de largo, glandulosos o peludos. Brácteas sedosas. Cabezuelas con 50 flores, de $6 \mathrm{~mm}$. de diámetro. Receptáculo désnudo. Es tna planta cosmopolita. Crece en todas partes de la República, en Centro y Sudamérica. Africa, Asia, etc. En el Valle de Mexico es abundante en al norte de la capital, en la Sierra de Guadalupe, Lechería, etc. También hay en las montafias del sur, como en la Cañada de Contreras, Lomas de Tacubaya, etc. Es rara en alturas mayores de $2500 \mathrm{~m}$. Prefiere los lugates asoleados. Florece en e lotoño y en el invierno. La encontré en la Cañada de Contreras en el mes de enero en plena floración.

AGERATUM CORYMBOSUM ZUCCAGNI: Pets. Syn. Pl, 2: 404, 1807.

Coelestinu coeruler Cass. Dict. Sci. Nat, 6.

Ageralum collestinum Sims, en Curtis's Bot. Mag. 42: p1, 1730.

Coelestina ageratoides HBK. Nov. Gen. \& 5 p. 4. 151.1820.

Codestina cormmbosa DC. Ptodr, 5: 108.1836.

Carelid coumbose Kuntze, Rev. Gen. PI. 1: 325 . 1891.

Es una planta subarbustiva o arbustiva hasta de $70 \mathrm{~cm}$. de alto: hojas muy variadas, en general ovadas, agudas y con la base cuneada o redondeada. de 2 a $11 \mathrm{~cm}$. de largo. A veces son glabras o en el envés con pelos grises, provistas de glándulas rojizas o pálidas. Cabezuelas de 8 a $10 \mathrm{~mm}$. de largo por 6 a 8 de ancho. Las flores son por lo genetal azules. Las tamas son grisáceas, peludas o finamente vellosas. Esta especie tiene numerosas variedades basadas en la forma de las hojas. Para referencia ver Proc. Amer. Acad. 49: $475-477.1913$.

Su nombre vulgar es "Cielitos" o "Mota morada". Crece de Sonora a Zacatecas. Texas y en el Valle de Mexico casi en todas partes, por ejemplo en el Pedregal, Sierra de Guadalupe, Cañada de Contreras. Prefiere los lugares asoleados y abiertos y casi nunca se encuentra en bosques tupidos. Abunda en los termenos calcáreos $y$ lugates secos. En Estados Unidos y en oțas partes es planta de jardinetia. 
SOCIEDAd BotÁNICA de MÉxico-Bol. 15-1953

OXYlobus Moc, A. Gray. Proc. Amer. Acad. 15: 25, 1879.

Referencia: Robinson, Revisión del género Oxylobus. Proc. Amer. Acad. 49: 483-487. 1913. Arbusto o subarbusto densamente velloso y glanduloso; hojas opuestas, subcoriaceas, no punteadas: cabezuelas cimoso-paniculadas: las brácteas del invólucro subherbáceas, con aristas: rẹceptáculo desnudo; aquenios con cinco aristas: vilano con 5 a 10 pajitas de distinta longitud. Este género fué separado recientemente de Ageratum, del cual se distingue por su tubo c rolino cotto y delgado, en la garganta abruptamente extendido, sus dientes no son tan agudos como el nombre indica (exy, agudo, lobo lóbulo) sino más bien anchos y extendidos. El vilano es muy corto y sus pajitas son tan partidas que su número es indefinido. Algunos botánicos no aceptan este género y siguen considerándolo como Ageratum. Nosotros no hemos encontrado ningún dato en la literatura botánica para justificar su anulación.

El género Oxylobus tiene tres especies nativas de México, siendo por lo tanto un géneró típicamente mexicano. Las tres especies crecen en las montañas clevadas. En el Valle de México hay dos especies: Oxylobus arbutifolius y $O$. adscendens.

Hojas enteras o algo aserradas, elipticas, de 2 a $10 \mathrm{~mm}$. de ancho. Los tallos tienen hojas en todo su largo: Oxylobus arbutifolius.

Hojas basales, en su mayoria obovadas, las del tallo. escasas y raquíticas: Oxyolbus adscenders.

OXYLOBUS ARBUTIFOLIUS HBK. A. Gray. Proc. Amet. Acad. 15.26.

Ageratum arbutifolium HBK. Nov. Gen. et Sp. PI. 4: 149.1820.

Pharia arbutifolia DC. Prodr, 5: 115.1836.

Phania trinervia DC. Prodr. 5: 115.1836.

Oxylobus trinervizas Moc. DC. Prodr. 5; 115, 1836.

Careliat arbutifolia Kuntze, Rev. Gen. P1. 1: 325. 1891.

Es planta arbustiva algo prostrada, tupidamento ramas hasta de $60 \mathrm{~cm}$. de alto cubiertas totalmente con hojas hasta 
SOCIEDAd BotÁNICA DE MÉxiCo.-Bol. 15-1953

arriba. Las hojas son subsésiles o cortamente pecioladas, elípticas, de 8 a $20 \mathrm{~mm}$. de largo y de 2 a 10 de ancho. Cabezuelas en corimbos tupidos en el extremo de las ramas, de 5 a $7 \mathrm{~mm}$. de largo por 2 a 3 de ancho. Flores blancas.

Esta especie crece exclusivamente en las montañas elevadas de más de $3000 \mathrm{~m}$. de altura. Humboldt la colectó por vez primera en

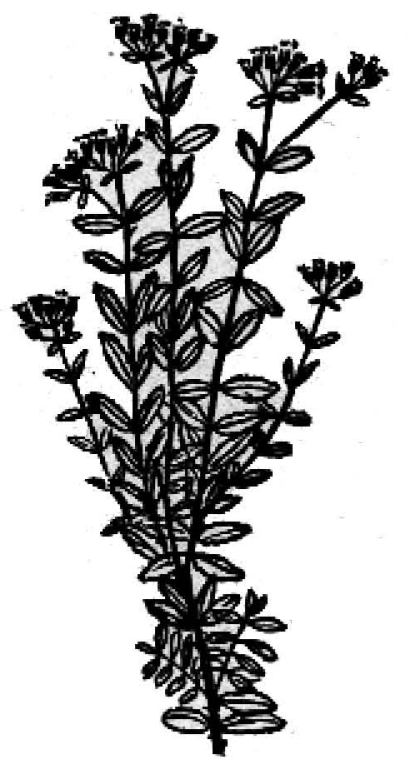

Oxylobus arbutifolins HBK.

el Naubcampetepetl (Cofre de Perote) a $3200 \mathrm{~m}$. En el Valle Central es abundante en las montañas del sur de la capital. en la Sierra de las Cruces, Serrania del Ajusco, en las faldas de los volcanes nevados. Nosotros la colectamos en las faldas del cerro San Miguel, en una altura de $3200 \mathrm{~m}$. Es un arbustito poco atractivo por su aspecto desaliñado y porque parte de las hojas y flores están secas o marchitas. A primera vista parece un Eupatorium y solamente un examen minucioso revela sus caracteres distintos. 
SOCIEDAd BotANICA dE MÉXICO.-Bol. 15-1953

OXYLOBUS ADSCENDENS, (Schultz Bip.) Robinson et Gtenm. Pros, Amer. Acad. $41 ; 272.1905$.

Ageratum adscendens, Schultz. Bip. Hemsi. Biol, Centr. Amer. Bot.

2: 80.1881 .

Carelia adscendens, Kuntze. Rev. Gen. P1. 1: 325. 1891.

Es una planta subarbustiva o herbácea. ptostrada, con hojas ba. sales; tallo berbáceo hasta de $50 \mathrm{~cm}$. de alto, con 3 o 4 pares de hojas obovadas o espatulado-obovadas, 2 a $4 \mathrm{~cm}$. de largo por 1 I 2 de ancho: dentadas, con peciolos cortos; cabezuelas en corimbos tupidos de unos $8 \mathrm{~mm}$, en la extremidad del tallo. Las flores son de un color azul pálido. Esta planta recuerda a uno de un Ageratum cortymbosum, por sus flotes azules y su porte en general.

Crece en las altas montañas del centro de la República. E1 tipo fué colectado en el Pico de Orizaba. En el Valle de México es planta escasa en la Serranía de Ajusco y en la Sierra de las Cruces. vegeta al lado del $O$ arbutifolius peto es mucho más rara. Es dificil encontrarla en los bosques densos ya que se pierde fácilmente entre los matorrales. Ambas especies florecen en los meses de lluvia de mayo a octubre.

\section{PIQUERIA. Cav. Icon. P1. 3: 18 pl. 235. 1795.}

Referencia; Robinson, Revision of the genus Piqueria, Proc. Amer. Acad. 42; 4-16. 1906. Este género, como el Ageratum y el Oxylobus pertenece a la subfamilia de las Eupatorieas. Fué dedicado por Cavanillés a A. Piquer, médico español del siglo Xvint. Es planta herbácea, ratas veces arbustiva. Las dos especies del Valle de México son herbáceas. Las hojas son opuestas, ovadas u oblongas, agudas. Cabezuelas homógamas de 3 a muchas flores. In yolucro campanulado o cilindrico, de dos filas de brácteas desiguales, flojamente imbricadas o subuniseriadas. Receptáculo desnudo, plano o convexo. Corolas tubulosas, blancas; el tubo cotolar a veces velloso o glanduloso, con la garganta ampliada: dientes de la corola ovados o deltoideos, suberectos. Anteras sin apéndice terminal, con la base obtu- 
SOCIEDAD BOTANICA DE MÉXICO.-BOL. 15-1953

sa. Aquenios con 4 ó 5 aristas prismáticas, con el ápice redondo. lampiños. Vilano ausente o con pocos pelos, anular o escamoso. Ramitas del estilo filiformes, exetcas o recurvadas. Este géneto tiene cinco especies en México. de las cuales dos crecen en el Valle de Mexico.

Hierba perenne, inflorescencia más o menos corimbosa. Base de los aquenios oblicua. Planta intensamente pilosa, hojas oblongas, anchas: Piqueria pilosa.

Planta subarbustiva a veces, los tallos inferiores leñosos, casi lampiña o escasos pelos, hojas angostas, oblongas: Piqueria trinervia.

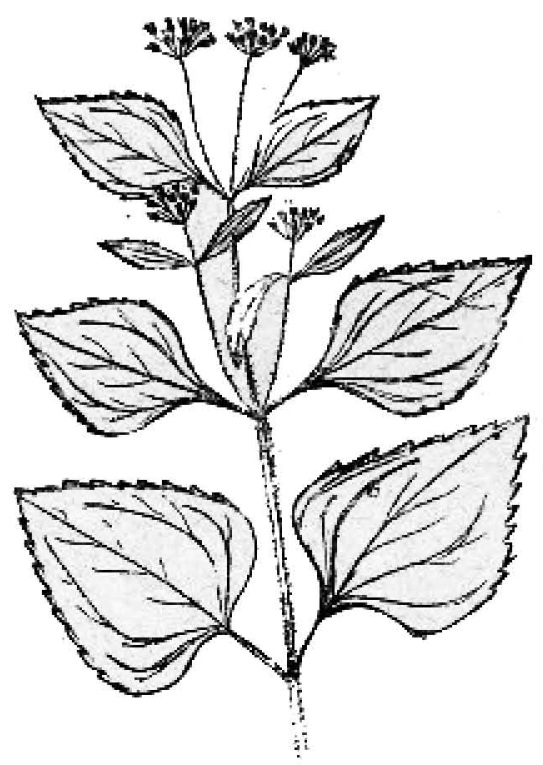

Piqueria pilosa HBK.

PIQUERIA PILOSA HBK. Nov. Gen. \& Spe. Pla. 4, I20.

Hierba perenne, ramificada, de 50 a $1.30 \mathrm{~cm}$. de alto, callo subcilindrico, muy peludo y glanduloso: hojas opuestas, pecioladas, ovadas, subacuminadas, asertadas, de 4 a $6 \mathrm{~cm}$. de largo por 2 a 4 de ancho: base cuneada: trinervada o quinquenervada: membra- 
SOCIEdAd BotÁnICA de MÉxico,-Bol, 15-1953

nosas y en los nervios vellosos. Peciolos de 4 a $10 \mathrm{~mm}$. de largo. gladuloso-vellosos. Inflorescencia cimoso corimbosa, cabezuelas con 4 flores blancas Brácteas del invólucro en número de 4 , elípticas. con los borde delgados y membranosos, con el ápice redondeado: corolas blancas, con el tubo corto, velloso-lanudo. con la garganta corta, los cinco dientes lanceolado-oblongos, algo agudos; aquenios con 5 aristas glabras de $2 \mathrm{~mm}$. de largo. Vilano ausente. El tipo de la especie fué colectado entre Capula y Pátzcuato por Humboldt. Crece en lugares altos y frios en las montañas del centro de la Re. pública. En el Valle de México abunda en las montañas del Sur. como en la Sierra de las Cruces. Pertenece a la variedad $\dot{P}$. pilosa var. Pringlei. Robinson 8 Seaton. En esta variedad los tallos y la inflorescencia no tienen glándulas y los pilos son blancos y encrespados. Esta especie prefiete los lugares sombreados en los bosques de Pinus y Abies. Florece de junio a septiembre.

PIQUERIA TRINERVIA Cay. Icon. PI. 3: 18. pl, 2i5 1795

Es una planta herbácea, perenne, a veces subarbustiva. Los tallos inferiores frecuentemente leñosos. Es muy ramificada. Tiene pocas hojas peto es muy tlorifera pues en los meses de lluvia sa llena de flores blancas. Las hojas son opuestas. angostas. lanceoladas $y$ acuminadas de tamaño variable, tienen tres nervaduras nuy marcadas. Esta especie es muy poco peluda y solamente en los rallos tiene escasos vellos. Las flores son como en la especie anterior. Es una planta muy atractiva y desde tiempos pasados ha sido objeto de cultivo. Es curioso que en la Horticulcura se la conore bajo el nombre de Stevia serrata. Indudablemente que se patece a una Stevia o a un Eupatorium y los botánicos aficionados la confunden frecuentemen. te con estos géneros. Se dice que sus flotes son fragantes. pero esto es una exageración, porque si tiene fragancia, ésta es apenas perceptible. Esta especie es nativa de México, América Central y Haiti. En toda la República crece abundantemente tanto en las regiones tropicales como templadas. Prefiere los lugares abiertos, asoleados y casi nunca se encuentra en bosques sombreados. En el Valle de México crece en todas partes hasta una altura de más o menos $2500 \mathrm{~m}$., asi 
Sociedad Botanica de México-BoL, 15-1953

que no vegeta en las montañas elcuadas. En el Valle de Míxico florece de julio a octubre. Sus nombtes vulgares son: "Hierba del tabardillo", "Hierba de San Nicolás", "yoloxiltie", "xexeniczal", "Cuapopolchi", "Alta teina", etc. Se usa mutho en la medicina popular contra el tifo, el paludismo, los cálculos biliares y hasta el rumatismo. Contiene ur alcaloide llamado piquerina.

\section{WEDELIA. Jacq. Enum. PI. Catib. 8; 1760.}

Este gentro que pertenece a la subfamilia Heliantheas tiene una sola espetie en el Valle de México: Wedelia bispida.

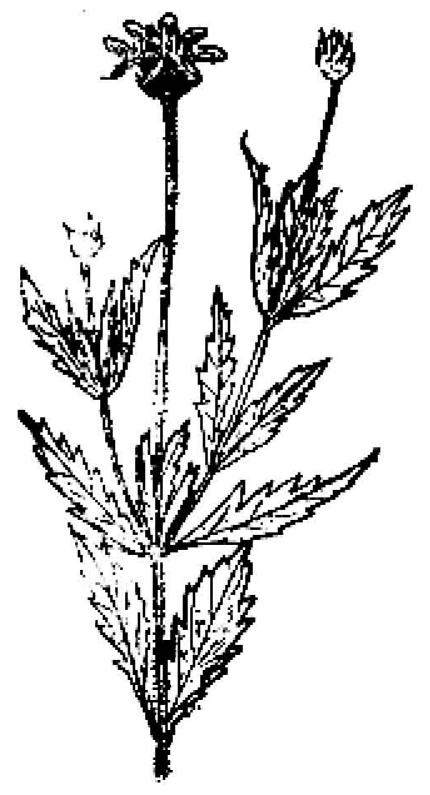

Wedalia hispida HBK.

WEDTILA HISPDA IJBK. Noq. Gen. Spe. 4: 169. L.jm 371.

Hierba perenne de 30 a $40 \mathrm{~cm}$. de alto, muy peluda. Hojas opuestas, lobuladas o dentadas. Las cabezuelas medianas, amarillas, 
SOciedad Botánica de México-Bol, $15-1953$

solitarias, heterógamas, con las flores periféricas femeninas liguladas $y$ las del disco tubulosas, hermafroditas, todas fértiles. Invólucro ovoide, campanulado, las brácteas biseriadas, las tes o cinco exteriores bastante herbáceas. Receptáculo plano o convexo, con las pajitas longitudinalmente plegadas, que abrazan las flores. Anteras con la base obtusa o cortamente aflechadas. L.os aquenios de las fiotes femeniras triquetros; los de las flores hermafroditas lateralmente comprimidos y con los márgenes cartilaginosos. El vilano de las flores del disco con dos aristas entre medio de las que tienen ascamitas. Es bastante abundante en la Sierra de Guadalupe y florece en los meses de julio a octubre. Su nombre vulgar es "clemolillo". Toda la planta es intensamente vellosa, áspera y rígida.

Resumen: El autor describe 9 especies de Astetáceas que ha ob servado en el Valle de México.

The author describes 9 species of Asteraceae which he bas observed in the Valley of Mexico. 